\title{
REFORMA DO ESTADO E DA EDUCAÇÃO NO BRASIL DE FHC*
}

José Luís SANFELICE*

E ste trabalho, composto por quatro ensaios, resulta de escritos para momentos diferentes, com um estatuto teórico próprio para cada um deles, mas com uma unidade, conforme os esclarecimentos prévios do próprio autor. O primeiro ensaio, "Estado moderno, cidadania e educação", visa

(...) identificar as complexas relações existentes entre o Estado moderno (a instituição política central da atual forma de produção de existência humana: 0 capitalismo), a cidadania (a qualidade política identificadora do ser social que nela se reproduz) e a educação (única prática social formativa ordenadajuridicamente pelo Estado capitalista). (P. 9)

Para tal intento são três os momentos destacados: 0 do liberalismo clássico, o do Estado de bem-estar social e do capitalismo atual.

No que tange ao liberalismo clássico 0 autor revisita duas obras de John Locke (1632-1704), ou seja: E nsaio acerca do entendimento humano e o Segundo tratado sobre o governo. D estaca que da mesma forma que Locke combate 0 inatismo das idéias, de maneira análoga opõe-se às teses que reivindicavam, na política, o poder inato. Todo 0 poder político seria decorrente de um pacto entre os homens, buscando organizar a convivência, com o Estado constituindo-se em uma estrutura máxima dessa ordem. Os riscos colocados aos direitos de igualdade, liberdade e propriedade do estado natural em que os homens viviam levou-os a superar aquela condição, por uma nova ordem pactuada. Seria a origem da sociedade política com o fim de preservar os direitos naturais de cada indivíduo e de todos eles, sendo o

\footnotetext{
* Resenha do livro de João dos Reis Silva Jr. (São Paulo: Xamã, 2002. 135p.).

* Professor livre-docente do Departamento de Filosofia e História de Educação (DEFHE) da Faculdade de Educação da unicAmp. E -mail: sanfelice00@ hotmail.com
} 
poder dos governantes derivado desta sociedade, pois ao Estado foi outorgado 0 ato de governar. Nesta nova ordem a condição humana, não mais natural, mas societal, instaura-se como cidadania. 0 público e 0 estatal distinguem-se e se relacionam enquanto o privado circunscreve as possibilidades de ação dos indivíduos, tudo de forma a garantir o pacto social. Em tese, os argumentos de Locke estariam presentes até hoje na ideologia liberal e no aparelho de Estado, embora possam ter adquirido várias roupagens através da história.

À luz de noções de Estado e política retirados da contribuição de Marx à questão, Silva Jr. atenta, entretanto, para a dimensão de que 0 estatal, o público e o privado, no âmbito da sociedade capitalista, constituem-se em meio ao movimento dinâmico e contraditório do capital que, se expandindo sempre, reconfigura o poder político e os espaços públicos e privados, bem como os direitos sociais e a cidadania burguesa. Isto implica contextualizar o pensamento de Locke na formação das bases econômicas para a institucionalização política do capitalismo com a instauração da cidadania como algo revolucionário, embora abstrata, uma vez que 'igualdade' e 'liberdade' contrapõem-se à propriedade privada de fato. Conseqüentemente, o filósofo propõe uma educação com as características da educação burguesa.

Perseguindo a mesma questão, Estado, cidadania e educação, no âmbito do denominado Estado de bem-estar social, o autor propõe seu entendimento a partir de uma análise marxiana do movimento do capital e assim procede.

O s pressupostos da análise são, portanto, aqueles clássicos do pensamento marxiano voltados para uma compreensão do movimento do capital, movimento este que condiciona a produção da vida humana, da cultura, da política e do Estado. Dentro desta lógica aponta-se que a superprodução do capital e seu expansionismo levam-no a deslocar-se geograficamente, temporalmente, bem como para as esferas sociais outrora organizadas pela esfera pública, dando origem a algo denominado a economia política do não:

(...) investimentos em não mercadorias, em serviços improdutivos com 0 objetivo de gerar riquezas marginais, pleno emprego e excesso de consumo, (...) a não produção de riqueza, ou seja, tinha início a artificialidade da economia capitalista, e, com isso, a destruição do processo civilizatório burguês por meio da mercantilização da esfera social da cidadania, isto é, dos direitos sociais. (P. 22) 
Produz-se, então, um fundo público para a manutenção do capitalismo, seja do seu ponto de vista econômico, bem como do macroacordo social.

D e forma correlata, na esfera social da cidadania, operacionaliza-se seu alargamento, por meio das políticas do Estado de bemestar social, constituindo-se este no poder central para a expansão do mercado, sem que se instaure a eliminação das possíveis crises de superprodução. Por meio da cobrança de impostos, o Estado torna-se 0 grande consumidor de capital, consagrando-se como a nova forma histórica do Estado burguês. É um Estado que "participa da reprodução do capital e da força de trabalho de forma diferenciada, ocupando assim lugar central na dinâmica do fordismo, parecendo não necessitar da produção de valor, de riqueza (...)” (p. 26). 0 público se privatiza enquanto o privado se expõe à publicidade e se transforma por critérios públicos.

0 autor, após cotejar pensadores que ensaiam teses explicativas sobre o Estado de bem-estar social, polemiza com as posturas políticas social-democratas para explicitar, retomando seu eixo central, que na nova forma histórica do capitalismo, o ser social e os direitos sociais são distintos do que foram à época de Locke.

O indivíduo é envolvido na gestão pública de seu país influindo na produção de políticas públicas por meio da mediação de instituições políticas que participam diretamente da produção de tais políticas no âmbito de Estado. Como corolário disso, os valores 'coletivos', 'públicos', 'político' e 'reivindicação' constituem-se em pilares da cidadania no período fordista. A reprodução social da força de trabalho por meios públicos, como parte da estratégia de administração do conflito de classes e de administração econômica, são inerentes à forma do ser social. Por outro lado, diante da necessidade estrutural da economia política do não, o consumo, como a outra face da produção em massa, coloca-se quase como um direito. Poderíamos dizer que o ser humano dessa época é o cidadão consumista, com agudo senso público, coletivo e reivindicativo. (P. 28)

É nesse quadro que se delineia a partir do século XIX , em especial nos países capitalistas mais avançados, a educação nacional, com seus avanços para uma educação democrática com orientação burguesa e fortalecedora do próprio Estado. As reformas educacionais virão em respostas às transformações amplas, seja do econômico ou do social. 
As condições que haviam se delineado para um modelo fordista demonstraram, entretanto, sérios sinais de esgotamento e novas políticas de austeridade monetária e fiscal foram acionadas, buscando-se reformas gerais propiciadoras de um novo estágio de desenvolvimento do capitalismo mundial. Paralelamente ao desmonte do Estado de bem-estar social e ao pacto social promovido por ele, busca-se construir uma nova ordem para o desenvolvimento do capital com implicações diretas nas esferas da cidadania e da educação. Instâncias sociais e de representação enfraquecem-se; agrava-se 0 desemprego estrutural e 0 fundo público, antes mantenedor de direitos, é reduzido drasticamente.

Enquanto a nova ordem convive com traços do velho - o fordismo - para consolidá-la ganham destaque intelectuais coletivos internacionais (Banco Mundial, Banco Interamericano de D esenvolvimento, Fundo Monetário Internacional, O rganização Mundial do Comércio, unESCO, CEPAL etc.) que arquitetam em favor do capital, especialmente 0 monetário, endividando os Estados perante os grandes fundos de aplicação privados, fazendo-os prisioneiros da lógica de mercado. Os custos são socializados pela via fiscal e em detrimento das áreas sociais. Os direitos sociais tornam-se mercadorias, com o deslocamento do capital para esferas sociais e políticas.

No Estado, restringe-se a esfera pública enquanto fortalece-se a privada. O Estado é forte, pouco interventor, mas o poder regulador, sob a forma do 'político', é o econômico. O Estado transfere suas antigas responsabilidades para a sociedade civil, mas avalia, financia, fiscaliza conforme políticas influenciadas pelas agências multilaterais.

A cidadania sofre restrições, uma vez que os direitos sociais tornam-se mercadorias. A condição humana passa a ser degradada mais violentamente e a nova cidadania é a cidadania produtiva. "A educação mercantiliza-se em todos os seus aspectos segundo a mesma matriz teórico-político-ideológica do Estado, na sua gestão e no seu conteúdo curricular, ambos baseados e legitimados pela ausência de sensibilidade com o social e por uma racionalidade científica instrumental" (p. 35). Para estas idéias muito contribuíram Hayek e Friedman.

As novas práticas conformam os sujeitos numa "sociedade cujo conteúdo histórico da cidadania consiste na forma de ser, cujos valo- 
res centrais são a produtividade, a utilidade, o individualismo e a competitividade, num contexto de ausência de reivindicação" (p. 36).

Enfim, há uma aguda crise do processo civilizatório da modernidade, que explicita sobremaneira as contradições da racionalidade capitalista. A tese que permeia este ensaio é a de que

ainda que o público (em seu sentido corrente) derive do privado (do âmbito da sociedade civil) e a ele se submeta, a compreensão da abrangência e da definição dessas esferas depende diretamente do movimento das relações sociais de produção que, por sua vez, constituem-se a partir da racionalidade do atual modo de produção: 0 capitalismo. Os espaços públicos e privados são fluídos, mas distintos e relacionados entre si. De toda forma, no capitalismo, o entendimento do público e do privado e de seu movimento somente pode se dar com a compreensão do movimento do capital e das crises do capitalismo, que instalam novos modos de conformação do publico e do privado que redesenham as relações entre o Estado e a sociedade e inauguram novos paradigmas políticos, alargando ou estreitando os direitos sociais, particularmente, para o que nos interessa, os relacionados ao direito à educação e sua racionalidade. Portanto, a compreensão das mudanças no conteúdo histórico da cidadania somente pode ser feita no contexto de redefinição das esferas pública e privada, especialmente em momentos de crise e mudança do capitalismo. (P. 23)

Para 0 autor, hoje tudo indica que vivemos um profundo momento de redefinição:

(...) a economia transforma-se na mais forte dimensão ideológica e em vez do poder político originar-se na sociedade, como propunha Locke, o que vemos é a emergência do poder político (com tênues mediações) na economia e sua submissão ao mercado. Impõe-se, pois, um regime político em cujo centro encontra-se uma racionalidade científica instrumental para que o individuo, sem sentimento de pertença a qualquer coletivo, assuma uma forma de ser social, na qual ele mais se nega, na qual ele se torna mais do que nunca mercadoria e a condição humana, historicamente, parece retroagir mais de 300 anos. (P. 37)

Este primeiro texto é basicamente a espinha dorsal e o pressuposto para os seguintes. Nos temas abordados posteriormente, várias vezes Silva Jr. remete ou retoma considerações aqui feitas garantindo de modo substantivo a unidade pretendida.

O segundo ensaio tem por título "A educação superior reformada: a produção da ciência engajada ao mercado e de um novo pac- 
to social". Suas referências iniciais conduzem o leitor ao seminário ocorrido em 1996 que teve por anfitrião o Ministério da Administração Federal e Reforma do Estado do Brasil (MARE), e que privilegiou o tema da necessária reforma do Estado e da mudança de paradigma da administração pública, tendo em vista a universalização do capitalismo. D ele participaram instituições internacionais e expressivos intelectuais de várias partes do mundo.

Os textos apresentados no seminário resultaram no livro Reforma do E stado e administração pública gerencial, organizado por Bresser Pereira \& Peter Spink e apresentado por Fernando Henrique Cardoso. Esta apresentação de FHC é explorada por Silva Jr. como antecipadora do novo paradigma político e do novo pacto social que se instauraria no país sob a batuta do próprio presidente.

A idéia central ali encontrada é de tornar o Estado "competente, eficaz, capaz de dar rumo à sociedade", hipotrofiando-se os poderes Legislativo e Judiciário, enquanto hipertrofia-se o Poder Executivo. Apesar de no discurso de FHC se preservar ao Estado a prestação de serviços básicos à população, não foram estes os resultados constatados ao término de seus mandatos.

$\mathrm{Na}$ universalização do capitalismo tornava-se imperioso enxugar o Estado, transferindo-se responsabilidades públicas para a sociedade civil. Um Estado enxuto e forte passou a se delinear, por um conjunto de reformas lideradas pelo próprio Poder Executivo, com a participação de algumas instituições e sem mediações das associações e entidades.

A lógica interna das reformas atrela-se à nova lógica do capital mundial que se desloca para setores nos quais nunca estivera e áreas, outrora públicas, são privatizadas. Os maestros deste novo movimento do capital destacam-se despudoradamente: BIRD/ Banco Mundial, FMI, BID, UNESCO, ONU e OTAN. Torna-se possível, então, visualizar um Estado reformado, forte no âmbito interno e submisso no plano internacional.

O passo seguinte das preocupações do autor é analisar a reforma da educação superior no contexto das reformas educacionais no mundo, o que é possível de se realizar através da constatação de que há semelhanças entre elas no que diz respeito a fazerem parte das mudanças sociais demandadas pela universalização do capitalismo. $\mathrm{O}$ ponto de partida são as transformações vividas pelos EUA no 
após Segunda Guerra Mundial, para se entender as mudanças ocorridas no que diz respeito ao papel do intelectual/ cientista na sociedade que passou a se delinear, bem como às redefinições que se impuseram ao mundo da ciência, às universidades, ao ensino superior como um todo e à formação dos indivíduos. D iscutem-se as continuidades e descontinuidades existentes entre os anos de 1960-1980 para, à luz deste referencial, analisar as reformas do Estado e da educação superior no Brasil. Conclui-se que a matriz orientadora da reforma do Estado está presente na reforma da educação superior e para a reforma nos outros níveis de ensino e modalidades. O rienta esse movimento reformista uma ciência que se tornou mercadoria e uma profissionalização cientificizada, centro de uma nova cultura política.

0 ensaio é finalizado com um delineamento crítico consistente a respeito da reconfiguração da educação superior brasileira, apontando para as profundas conseqüências quanto à identidade institucional da universidade.

"A consolidação do campo profissional na reforma do ensino médio" é o título do terceiro ensaio e que está umbilicalmente unido aos textos anteriores, por enfocar uma nova temática, mas na mesma ordem lógica das mudanças implementadas na sociedade brasileira sob a presidência de FHc. Como então compreender a reforma do ensino médio no contexto em que se transformou a sociedade brasileira no final do século XX?

A resposta objetiva se resume a uma afirmação: trata-se de "uma ação política para mudança social tendo como elementos que fundam essas mudanças a economia e o trabalho nos países emergentes" (p. 76). É "uma intervenção consentida realizada pelas autoridades educacionais nos moldes das agências multilaterais, no contexto da universalização do capitalismo" (p. 76), com todos desdobramentos daí decorrentes.

A análise que acompanha os documentos de referência das reformas educacionais vai revelando a tecitura da nova cultura política e seu assentamento epistêmico no neopragmatismo e na ciência instrumentalizada.

D estacam-se em especial os novos parâmetros para a formação do trabalhador através da educação, tendo em vista a universalização do capitalismo, do trabalho e da própria educação. Neste âmbito a 
reforma imposta ao ensino médio tornou-se fulcral e os seus pressupostos e conseqüências são aqui dialeticamente estudados.

Por último temos o ensaio "Uma estratégia mercantil para a concretização da Reforma Educacional" que, ao leitor já suficientemente municiado pelos estudos anteriores, revela a permanência de estrutura de análise do autor, voltada agora para as novas tendências da formação dos professores, no contexto do movimento reformista da educação no Brasil. São destacados três programas de educação a distância da Secretaria de Educação a Distância (SEED): o Programa Nacional de Informática na Educação, o TV Escola e o Programa de Formação de Professores em Exercício.

A análise dos referidos programas leva o autor a algumas constatações contundentes quanto às implicações políticas e teóricas dessa modalidade educacional, uma vez que a formação de professores, no conjunto da nova ordem, torna-se uma estratégia da reforma educacional, a ser concretizada pela prática docente no cotidiano escolar. Visa-se um professor produtivo e sem a valorização consistente de sua formação, mas que sobrevaloriza a tecnologia educativa como apoio ao educador: uma porta de entrada do capital industrial.

Ao longo de todo o trabalho o autor exercita forte interlocução com pensadores clássicos, cientistas políticos e sociólogos estrangeiros e nacionais. Emerge sempre uma análise reflexiva, crítica e polêmica. $\mathrm{Na}$ contramão da hegemonia do discurso neoliberal, sua contribuição deverá ter boa acolhida nos cursos universitários de formação e em programas de pós-graduação nos quais se dá atenção ao momento histórico vivido pela sociedade brasileira neste princípio de século XXI. $\mathrm{O}$ livro pode exigir do leitor alguma familiaridade com a filosofia, com a sociologia e com a política educacional, mas ao mesmo tempo poderá se constituir também numa excelente iniciação. 